Tarih Kültür ve Sanat Araştırmaları Dergisi

Revue des Recherches en Histoire Culture et Art

مجلة البحوث التاريخية و الثقافية والفنية
Vol. 6, No. 6, December 2017

Copyright (C) Karabuk University

http://kutaksam.karabuk.edu.tr

\title{
DOI: 10.7596/taksad.v6i6.1325
}

\section{What Drives Students of Vocational Training Program? An Investigation on the Significance of Foreign Language Acquisition}

\author{
Irina M. Solodkova1, Elena V. Grigorieva², \\ Liliya R. Ismagilova ${ }^{3}$, Oksana V. Polyakova4
}

\begin{abstract}
The paper dwells on the distinguishing the motives that drive students of vocational training program in terms of foreign language acquisition being the main component of future employment success. In fastchanging world which is teemed with new challenges and career patterns foreign language acquisition is viewed as a foremost aspects of promotion. The aim of the current study was to identify the main motives that drive students of vocational training program for foreign language acquisition and later equip higher education authorities and teaching staff with the data to improve language education complying with the students' requirements. To find out internal and external motives of the students enrolled to the program at The Educational Center for Professional Communicative Training of Kazan Federal University a questionnaire survey was organized. The results of the research identify that there are differences in students' priorities of external and internal motives and there is a prevalence of the internal ones. It is accounted for by the fact that students of the program realize the significance of foreign language acquisition for their personal needs and future professional activity. But practically all of them emphasized the same personal and interpersonal factors of internal motivation. The obtained findings will be exploited as recommendations in designing the syllabus and will be of great help in choosing the appropriate forms and techniques in carrying out the course.
\end{abstract}

Keywords: Motivation, Foreign language acquisition, Motive, Internal motivation, External motivation.

\footnotetext{
${ }^{1}$ Kazan Federal University, Institute of Management, Economics and Finance. E-mail: imsold@mail.ru

${ }^{2}$ Kazan Federal University, Institute of Management, Economics and Finance.

${ }^{3}$ Kazan Federal University, Institute of Management, Economics and Finance.

${ }^{4}$ Kazan Federal University, Institute of Management, Economics and Finance.
} 


\section{Introduction}

Due to the integration of Russia into the world economic, scientific and cultural environment, the improvement of academic achievements of future specialists has gained crucial importance. Foreign language skill in this concern acts as one of the tool, which might be used to achieve required level of specialists' competitiveness (Khusainova \& Rahmatullina, 2014). It is said to stimulate specialists' engagement into intercultural, inter-ethnic dialogue, to analyze their activities in the context of the practices of the world's leading powers, to widen their mindset, provide personal and professional growth. Considering this, the most important component of each student's culture is professional values that will allow him to better orientate himself in the world of work and, ultimately, become the basis for motivating his professional and career growth (Galishnikova et al, 2016). "Motivation is a complex, actively and continuously discussed phenomenon which found its reflection in all actions observed in the society, whether we speak about professional, educational or everyday matter" (Grigoreva \& Solodkova, 2015: 341).

This term is widely explained in the researches of educators, psychologists, linguists like Rubinshtein $S$., Maslow A., Myasishchev V., Bozhovich L., Zimnyaya I., Vygotsky L., Ushinsky K.D., Leontiev A., Jacobson P., Markova A., Matis T., Matyukhina M., Maslyko E., Grigoryan S., Kolechenko A., and others. Motivation is mostly understood as the inner drive of a person to carry out certain activities.

Scientists provide different reasons for being a motivated person. A motivated student is one who makes efforts in educational activities in order to improve his results. It is motivation that "makes the studying process both interesting and productive" (Ur Penny, 1996). Papalia A. considers motivation as: "readiness to achieve certain results in educational activities; an impulse that causes a person to act in a certain way; an internal stimulus that requires active interest" (1986). "Motivation consists of a set of different motives that motivate a person to perform basic activities, the process of the motive's action" (Kolechenk, 2005).

The motive appears in the mind of a person as an object or goal, to which, in the final analysis, behavior is directed. The motive is always connected with the processes of cognition: perception, thinking, memory, speech. The goal is called the immediate, necessarily tangible result, to which behavior is currently directed. I.A. Zimnyaya calls motivation "the launching mechanism" of all human activity: whether it is work, communication or cognition. Only tangible, real, phased and final result nourishes and supports motivation. If there is no success, then the motivation fades and this negatively affects the performance of the activity. In addition to the needs, motives and goals, as incentives for human behavior, they also consider interests, aspirations, desires and intentions.

In preparation for professional activity, there are two interrelated types of motives: academic and professional. Professional motives are adequate to the ultimate goal of education. Academic motives are laid in the very process of learning, and therefore are indispensable and necessary for the successful implementation of educational process.

The aim of the current study is to identify the main motives that drive students of vocational training program for foreign language acquisition and so to equip teachers, educators and higher education authorities with the data to improve language education due to the students' requirements.

Many students come to the university with a consciously negative attitude to the foreign language acquisition. This academic subject is perceived as unnecessary, knowledge it provides is not considered as a future factor of competitiveness on the labor market. This situation could be explained by a number of reasons: teaching style (the same textbooks; uninteresting exercises, not appealing to students' age and interests; lack of visibility; absence of real life examples; simulations and game like activities; no rapport in the group; ignoring the principles of personality-oriented learning; frequent change of teachers; multilevel 
language groups; limited clock grid; lack of modern equipment and gadgets, proper methodological support, etc. (Grigoreva \& Solodkova, 2015). The task of the university teacher in these circumstances is to revive students' attitude to the studied discipline, to show that studying a foreign language can be interesting and applicable in practice. In this regard, the motivational aspect of language training in a nonlinguistic institution of higher education has become extremely important.

The increase in the motivation to study of FL (foreign language) in an economic HEl passes several stages. Initially, students are supposed to learn culture-through-language studies material associated with the specifics of the HEI (for example, the economic realities of English-speaking countries, their traditions, customs, banking system, the education system, the economy of the country, etc.). This also includes the etiquette and aesthetics in foreign-language communication, which makes education multilingual and multicultural (Pulverness et al, 2017). When teaching students intercultural communication special attention is paid to the content of the cultural component of vocational training, which includes familiarity with etiquette as established norms of behavior in a foreign society (telephone conversation, behavior in a hotel, family visit, etc.) and with art and artwork of the studied language country the as forms of aesthetics. At the next stage, students receive information about the system of the British and American economy. The main thing in the forming motivation to study $\mathrm{FL}$ in a non-linguistic institution is to demonstrate the practical importance of knowledge, the possibility to use it in future professional activities (Grigorieva et al, 2015). While learning FL students participate in round table discussions, scientific and practical conferences, develop collective and individual projects along with accomplishing practical exercises (Ismagilova \& Polyakova, 2016). Such activities allow them to percept FL as a means of acquiring new professional knowledge and initiate the change in attitudes toward learning the language.

The teacher indirectly influences the formation of the motivational level, creates prerequisites and forms the grounds to acquire personal interest in the work. In this regard, the teacher's professionalism is of particular importance, it consists of the possession of all the tools of motivational media, the knowing all types and subtypes of motivation and their reserves. The foregoing gives the right to characterize the main types of motivation. In pedagogical psychology, it is common to distinguish two main types of motivation - internal and external (see Table 1).

Table 1. Structure of students' motives for learning a foreign language

\begin{tabular}{|l|l|l|l|}
\hline \multicolumn{2}{|c|}{ Motivation } \\
\hline External & $\begin{array}{l}\text { Civil duty to the country, } \\
\text { parents, teachers group, } \\
\text { future employer in good } \\
\text { knowledge of a foreign } \\
\text { language, its application in } \\
\text { practice }\end{array}$ & $\begin{array}{l}\text { 1. Communicative } \\
\text { Carrying out communication } \\
\text { with representatives of } \\
\text { different cultures; reading } \\
\text { original books; improvement } \\
\text { of knowledge in subjects; } \\
\text { friendly correspondence; } \\
\text { traveling and so on. }\end{array}$ \\
\hline $\begin{array}{l}\text { Narrowly } \\
\text { personal / }\end{array}$ & $\begin{array}{l}\text { Opportunity to work for a } \\
\text { foreign 2. Linguistic } \\
\text { implementation of seasonal } \\
\text { «projects of life» (Work \& Travel); }\end{array}$ & $\begin{array}{l}\text { Mastering new speech } \\
\text { patterns, phraseological units, } \\
\text { idiomatic expressions; } \\
\text { improving the professional }\end{array}$ \\
\hline
\end{tabular}




\begin{tabular}{|l|l|l|l|}
\hline & $\begin{array}{l}\text { participation in international } \\
\text { youth forums trainings, } \\
\text { receiving grants, etc. }\end{array}$ & 3. Instrumental & $\begin{array}{l}\text { Increase FL knowledge through } \\
\text { additional classes or language } \\
\text { courses and clubs, an } \\
\text { additional qualification } \\
\text { program "Translator in the } \\
\text { field of professional } \\
\text { communication" }\end{array}$ \\
\hline
\end{tabular}

External motivation is the result of an external stimulus, which is embodied in the requirements of society, the state, the educational institution, the employer, the family, the so-called social motives. External motivation exists in two varieties: broad social motivation and narrowly personal. Internal motivation arises from the desire to study a particular field of knowledge based on personal interest, motivation for self-realization and self-actualization, satisfaction of cognitive needs. This type of motivation is divided into communicative, linguistic and instrumental (Grigoryan, 1979). Communicative type of internal motivation can be called the main one, since communication is the primary goal of students to learn FL. This type of motivation is the most difficult to preserve since students are learning FL in artificially created conditions. Communication in the $\mathrm{FL}$ is conditional, which brings it closer to the communication on the stage, thus it is important to appeal constantly to the imagination of students.

Studies have shown that external motivation among students of a non-linguistic HEl prevails the internal one. Most students study FL only because they are afraid of getting low scores, failure the exam, the prestige of attended language courses; requirements of parents. However, according to many researchers (Ilkevich BV, Ouadani F., Malone T.W., Lepper M.R., etc.) it is the internal motivation that is potentially important for the development of motivation. Its increase also leads to the strengthening the connection of educational activities with the future profession of students.

Malone \& Lepper (1987), state the following personal (P) and interpersonal (I) factors for promoting motivation: challenge $(P)$, curiosity $(P)$, control $(P)$, fantasy $(P)$, cooperation $(I)$, competition $(I)$, recognition (I).

On the basis of these findings, it can be concluded that the personal factors of internal motivation presuppose: the foreign language teaching in the optimal behavior for students (the complexity of the material, the pace); career orientation; achieving students positive self-esteem; setting up problems to activate the mental activity; the congruence of the teaching content with the needs and individual, age peculiarities of students; using game forms of teaching and simulating aimed at imitating the situations of professional and everyday communication. Interpersonal factors are aimed at success, the development of a positive self-concept of young people, leadership, and the establishment of favorable trust relations, empathy, team-spirit.

\section{Methods}

The main methods used for this research are analysis of progressive psychological and pedagogical experience, observation, theoretical analysis and questionnaire survey. The survey was conducted among 
78 students of the program at the Educational Center for Professional Communicative Training within the Department of Foreign Languages in Economics, Business and Finance, the Institute of Management, Economics and Finance, Kazan Federal University. The participants of the survey are students of different language proficiency and both genders. There were mainly 2 types of questions: open questions which supposed students to choose the variant which appeals to them and closed questions requiring the respondents to circle 'yes' or 'no' answer. Participants' responses were confidential and for research purpose only.

The aim was to determine what type of motivation, internal or external prevails among students of the program and which factors of motivation are prioritized and essential for them. The questionnaire comprised 10 questions. The researchers tried to find answers for the questions specifically suited to the aim of the research, like: reasons for studying foreign language (Q3); subject matter of motivation for student (Q5); factors influencing self-development (Q6); (Q7) is designed to find out what factors influencing students in their foreign language acquisition; (Q9) concerns students' personal and interpersonal factors of internal motivation.

The data analysis of written responses to the questionnaire employed a basic qualitative enquiry technique. The answers were counted and written opposite the questions in percentage received.

\section{Results}

The results obtained gave the evidence that of the 78 students who completed the questionnaire, 19 students (24\%) - demonstrate the prevalence of external motivation of foreign language acquisition, 59 students $(76 \%)$ - demonstrate the predominance of internal motives. It proves the importance of foreign language acquisition for their future career and the necessity to use foreign language for their personal purposes. This data allowed us to rely on them in investigating the issue (Fig. 1).

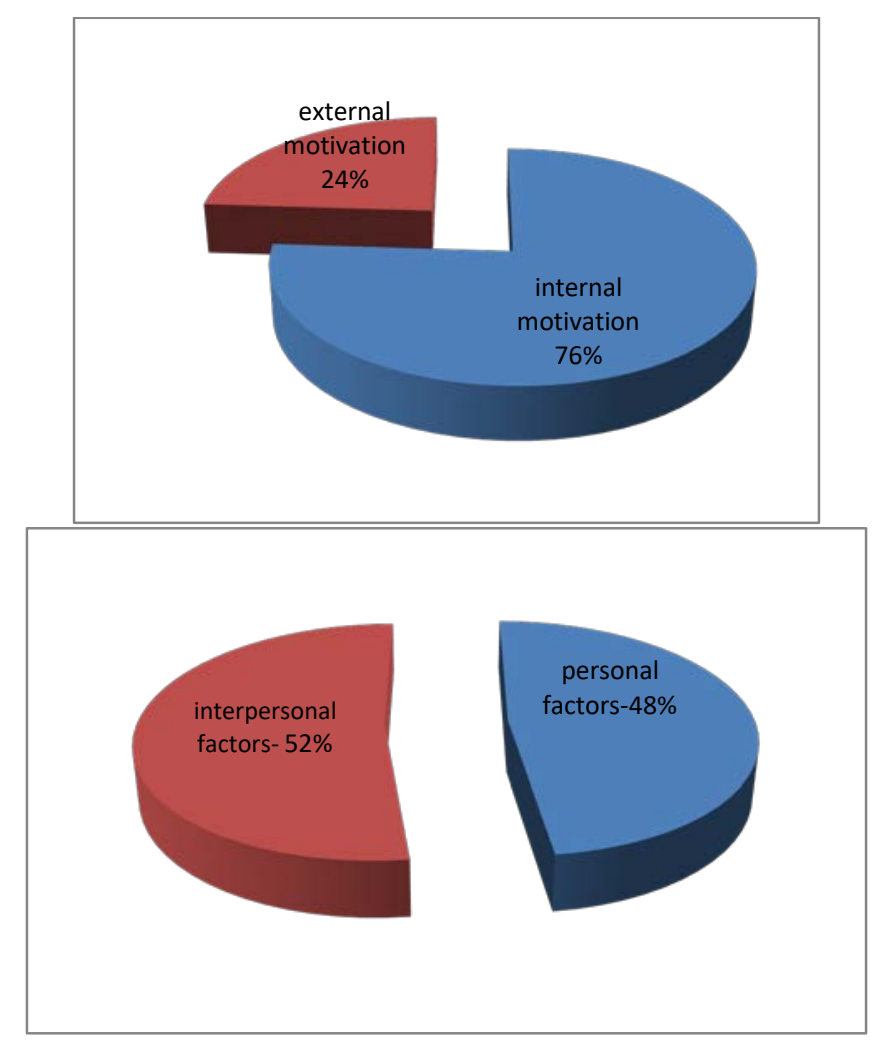

Figure 1. Students' motivational aspects 
Having found that students of the program are driven by the internal motives, moreover, the division between personal and interpersonal factors is not clear, the researchers analyzed them according to students' priorities to each individual factor (Fig.2).

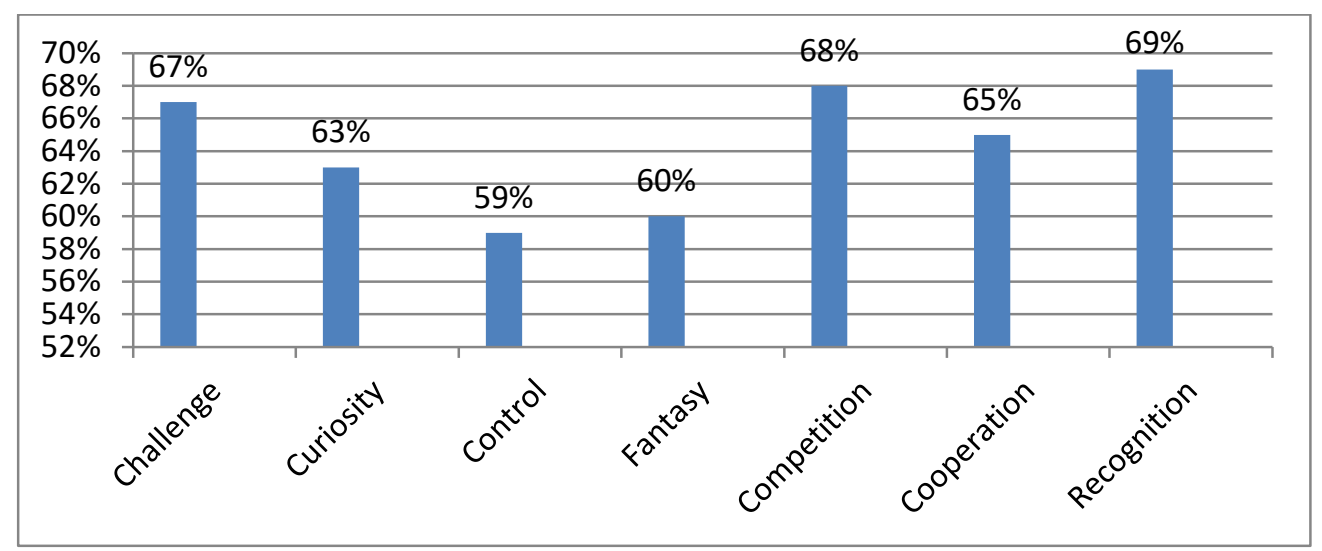

Figure 2. Factors of internal motivation

The results showed the almost equal percentage. 52 students (67\%) consider challenge as the factor of their personal motives when they are working toward personally meaningful goals requiring the optimal level of difficulty; 49 students (63\%) define curiosity as something in the physical environment that attracts the student's attention; 46 students (59\%) refer to control as the desire to control what happens to them; 47 students (60\%) point out fantasy as the use of mental images of things and situations that are not actually present to stimulate their behavior; 53 students (68\%) consider competition as the way to feel satisfaction by comparing their performance favorably to that of others; 51 students (65\%) appeal to cooperation to feel satisfaction by helping others achieve their goals; 54 students (69\%) define recognition to feel satisfaction when others recognize and appreciate their accomplishments.

The results of the research identify that there are differences in students' priorities of external and internal motives and there is a prevalence of the internal ones. It is accounted for by the fact that students of the program realize the significance of foreign language acquisition for their personal needs and future professional activity. But practically all of them emphasized the same personal and interpersonal factors of internal motivation.

\section{Discussion}

Based on the examined types of motivation, the authors arrived at a decision that in order to increase the motivational level of foreign language learning in a non-linguistic HEl, it is necessary to meet the following conditions:

- Take into account students needs, their interests, ambitions, mindset, temperament and character traits;

- Use the certain motivational strategies in teaching. These include: the use of authentic professionoriented information; game cases; video and audio records for teaching listening, reading, speaking, writing; cooperation in large and small groups (high-achieving students jointly with the low-achieving ones) in order to develop speaking skills, interchange views on the basis of collaboration; a scenario of possible professional situations to improve the use of professionally-oriented vocabulary, the ability to communicate, negotiate, make presentations; texts and dialogues reproduction; 
- Organize the learning process based on the principle of skills integration. For example, when practicing reading, use listening at the pre-text stage and speaking in the post-textual, respectively, the improvement of writing as a homework assignment;

- Involve students in the learning process to the greatest possible extent. Each task should be aimed at students provoking to speak, to express ideas, to argue, to fall back on past experience. The classroom hour should be imbued as much as possible with the students' burst of speech;

- Organize the proper control of the foreign language lesson. There should be the accurate design of the lesson, the learning goals available to realize, clear instructions to do assignments, etc.

The above mentioned means of maintaining a high level of motivation to study foreign language can also be supplemented by the following: the enthusiasm of the teacher; the appropriateness of the learning content to the level of knowledge and age; a variety of methods used and learning technologies; mutual intelligibility between the teacher and students; use of concrete, comprehensible examples.

The subject appeals to the students, they have the opportunity to participate in designing, developing, analyzing the material, they feel responsible for participating in any project and have more successful than negative experience and failures in learning.

\section{Summary}

Educators search for more productive ways how to provoke interest in foreign language acquisition. Motivational aspect is crucial in overall process of knowledge acquisition and is hard to be maintained and retained. In pedagogical psychology, it is common to distinguish two main types of motivation - internal and external. External motivation is the result of an external stimulus, the so-called social motives. Internal motivation arises from the desire to study a particular field of knowledge based on personal interest, motivation for self-realization and self-actualization, satisfaction of cognitive needs.

There have been distinguished several means of maintaining a high level of motivation to study foreign language: satisfying students' needs, use appropriate materials to stimulate their interest, using skill integration principle in organizing learning practice, establishing control backed up with a proper feedback, creating positive rapport in the classroom.

These fruitful external motives which certainly would provide fertile soil for successful development of internal motives. The results showed the almost equal percentage of preferences in personal and interpersonal internal motives.

\section{Conclusion}

Each subject supposes the problem of motivation in learning. However, the problem of motivation to study foreign language in a non-linguistic HEl is especially acute. This, in particular, is determined by the fact that foreign language acquisition in the atmosphere of the native language makes the subject an artificial means of communication. The teacher is constantly upon the look of the most optimal ways to create a "natural environment" of communication and the conditions to maintain the high motivational level.

Motivational aspect has crucial significance to make more active all psychological processes - cogitation, perception, appreciation and assimilation of foreign language material. Increasing motivation, development of cognition and intellectual activity, ultimately, will increase the effectiveness of the learning process. The quality of foreign language training will be the factor of specialist competitiveness in the labor market in the future. 


\section{Acknowledgements}

The work is performed according to the Russian Government Program of Competitive Growth of Kazan Federal University

\section{References}

Galishnikova, E. M.; Baklashova, T. A. \& Khafizova, L. V. (2016). Formation of Student's Tolerance in Multicultural Environment When Teaching a Foreign Language (KFU Experience, Kazan, Republic of Tatarstan, Russia). IFTE 2016 - 2nd International Forum on Teacher Education, 12, 38-44.

Grigoreva, E. V. \& Solodkova I. M. (2015). Teaching English for undergraduate students: Motivational aspect. Mediterranean Journal of Social Sciences, 6(1), 341-345.

Grigorieva, E. V.; Ismagilova, L. R. \& Solodkova, I. M. (2016). Comparative analysis of oral and computer based types of assessment in teaching English for students of economics, business and finance. ERPA International Congresses on Education 2015.

Grigoryan, S. T. (1979). On the question of the correlation of needs and motivation of students in the study of a foreign language. Age features of the cognitive activity of schoolchildren and students. Moscow.

Grigoryeva, E. V. \& Solodkova, I. M. (2015). Foreign language skill as a component of self-development procedure: undergraduate and graduate level. ICIBSOS The 4th International Congress on Interdisciplinary Behavior and Social Science 2015, Kazan Federal University, Russia, 22-23 October, 2015. Pp. 95-99

Ismagilova, L. R. \& Polyakova, O. V. (2015). Problem of managers' communicative competence formation. Social Sciences and Interdisciplinary Behavior - Proceedings of the 4th International Congress on Interdisciplinary Behavior and Social Science, ICIBSOS 2015, 109-114.

Khusainova, A. A. \& Rahmatullina, A. R. (2014). English Language Training Volunteer Program as a New Reality for Russia and its Social Benefits. Procedia-Social and behavioral sciences, 152, 1101-1107.

Kolechenko, A. K. (2005). Encyclopedia of Pedagogical Technologies: A Handbook for Teachers. St. Petersburg: KARO.

Lepper, M. R. \& Malone, T. W. (1987). Intrinsic motivation and instructional effectiveness in computerbased education. In R. E. Snow \& M. J. Farr (Eds.), Aptitude, learning, and instruction: Vol. 3. Cognitive and affective process analysis (pp. 255-286). Hillsdale, NJ: Erlbaum.

Papalia, A. (1986). A research Report on Motivating the Language Learner. NYSAFLT Language Association Bulletin, 38.

Pulverness, A.; Klimova, I. I.; Kalugina, O. A.; Vasbieva, D. G. \& Ismagilova, L. R. (2017). The formation of students' intercultural communicative competence in an English language learning environment at a nonlinguistic higher school. XLinguae Scientific Language Journal, 10(4), 381-397.

Ur Penny. (1996). A course in language teaching. OUP. 